\title{
Pendampingan EPS-TOPIK (Employment Permit System-Test of Proficiency in Korean) bagi Calon Pekerja Migran Indonesia dari Propinsi D.I. Yogyakarta
}

\author{
Suray Agung Nugroho \\ Departemen Bahasa dan Sastra, Fakultas Ilmu Budaya, Universitas Gadjah Mada \\ Posel: suray@ugm.ac.id
}

Tim Pengabdian kepada Masyarakat:

Febriani Elfida Trihtarani, Hwang Who Young, Iva Hanani, Suhandano, Suray Agung Nugroho, Tri Mastoyo J.K.

\begin{abstract}
The relatively low numbers of Indonesian migrant workers who passed the EPS-TOPIK (Employment Permit System-Test of Proficiency in Korean) as a prerequisite to work in Korea as well as the relatively small numbers of Korean language instructors with experiences and backgrounds in Korean language teaching are the rationales that prompted Korean Language and Culture Program, Faculty of Cultural Sciences UGM to carry out this Community Engagement Activity. As an initial engagement, we carried out an EPS TOPIK Try Out test to 48 migrant worker candidates who currently learn Korean language at 5 Korean Language Courses in Yogyakarta Province. This is the first engagement activity planned to be carried out continuously as our endeavor to solve the aforementioned problems. Based on the results of the Try Out test, we observed that they need to brush up their Korean competency in understanding Korean conversations and in using vocabularies in the right context. We will use these initial findings as a basis to make a Learning and Teaching Material suitable for both the learners and the instructors. We plan to make the materials by incorporating both the learners and the instructors' difficulties in learning and teaching Korean language with EPS-TOPIK as the starting point. It is also worth to note that in many Korean Language Courses across the country, the main Korean language instructors are the returned migrant workers themselves. Albeit being able to write and talk in Korean, they had no prior educational background of Korean language. Thus, we also plan to continue setting up methods to teach them Korean language in a series of Training for Trainers program (the next Community Engagement Activities) in cooperation with related institutions like BNP2TKI (Agency for the Protection and Placement of Indonesian Migrant Workers). We deem it necessary to go on with the plan as the Government to Government Agreement between Korea and Indonesia in dispatching Indonesian migrant workers to Korea is still in effect.
\end{abstract}

Keywords: EPS-TOPIK, Korean Language Competency, Indonesian Migrant Workers

\begin{abstract}
Abstrak
Belum maksimalnya tingkat kelulusan para calon pekerja migran Indonesia (PMI) dalam ujian EPS-TOPIK (Employment Permit System-Test of Proficiency in Korean) serta masih kurangnya jumlah pengajar bahasa Korea yang berlatar belakang pengajaran bahasa Korea di lembagalembaga pelatihan bahasa Korea mendorong Prodi Bahasa dan Kebudayaan Korea FIB UGM untuk memulai sebuah kegiatan Pengabdian kepada Masyarakat (PkM) dengan tema yang
\end{abstract}


berkaitan dengan problema tersebut. Untuk itulah, sebagai langkah awal, prodi mengadakan try out ujian EPS-TOPIK kepada 48 calon PMI yang tengah belajar bahasa Korea di lima Lembaga Kursus \& Pelatihan (LKP) Bahasa Korea di Provinsi DIY. Kegiatan ini adalah PkM perdana yang didesain untuk dilaksanakan secara berkelanjutan sebagai kontribusi langsung dalam pemecahan masalah. Berdasarkan hasil try out yang menunjukkan masih perlu ditingkatkannya kemampuan bahasa Korea para peserta, terutama dalam hal memahami percakapan dan pemakaian kosakata secara tepat, maka prodi berencana untuk menggunakan hasil ini sebagai landasan untuk membuat bahan ajar terkait EPS-TOPIK yang dapat digunakan oleh peserta didik ataupun para pengajar dalam mempelajari dan mengajarkan materi-materi dalam EPSTOPIK (Rencana PkM tahap 2). Selanjutnya, prodi bekerja sama dengan BP3TKI dan instansi lainnya berencana untuk menyelenggarakan Training of trainers, yaitu lokakarya pengajaran bahasa Korea untuk para pengajar bahasa Korea di LKP-LKP seluruh Indonesia (Rencana PkM tahap 3). Semua itu didasari dengan fakta bahwa kerja sama Goverment to Government ( $\mathrm{G}$ to $\mathrm{G}$ ) antara Korea dan Indonesia dalam pengiriman PMI terus berjalan. Oleh karena itu, kegiatan PkM berkelanjutan ini didesain untuk memberikan sumbangan awal prodi dalam mengatasi rendahnya penyerapan calon PMI ke Korea yang disebabkan oleh rendahnya kemampuan bahasa Korea para calon PMI.

Kata kunci: EPS-TOPIK, kemampuan bahasa Korea, pekerja migran Indonesia (PMI)

\section{Pengantar}

Korea Selatan merupakan salah satu negara tujuan yang diimpikan oleh para calon tenaga kerja asing, termasuk yang berasal dari Indonesia. Hal ini disebabkan oleh para pekerja asing di Korea tidak hanya menerima gaji minimal 1.560.000 Won atau setara dengan 18 juta rupiah per bulan, namun mereka juga mendapatkan berbagai fasilitas seperti tempat tinggal, konsumsi selama bekerja, dan berbagai asuransi (asuransi kesehatan, asuransi kecelakaan kerja, asuransi kepulangan, asuransi dana pensiun, dll.). Menurut data BNP2TKI (Badan Nasional Penempatan dan Perlindungan Tenaga Kerja Indonesia) hingga akhir tahun 2017, jumlah pendaftar untuk bekerja di Korea Selatan mencapai 23.994 dalam memperebutkan 5.000 kuota yang dipersiapkan oleh Korea Selatan. Namun, Indonesia baru mampu menempatkan sekitar 2.586 orang pekerja migran Indonesia (PMI) dari sekitar 5.000 kuota yang dapat diisi. Setelah menilik lebih jauh, salah satu penyebab hal tersebut adalah adanya fakta bahwa dari 23.994 pendaftar tersebut banyak yang tidak lulus ujian Employment Permit System-Test of Proficieny in Korean (EPS-TOPIK) yang merupakan salah satu syarat untuk maju ke tahap selanjutnya guna terpilih sebagai PMI.

Belum maksimalnya tingkat kelulusan EPS-TOPIK disebabkan oleh beberapa hal. Pertama, kurang maksimalnya pemahaman tentang EPS-TOPIK serta kurangnya frekuensi latihan ujian karena kurangnya lembaga yang secara periodik menyelenggarakannya. Kedua, kurangnya variasi buku pembelajaran EPS-TOPIK untuk calon pekerja Indonesia. Ketiga, kurangnya pengajar bahasa Korea yang berlatar belakang pengajaran bahasa Korea untuk orang asing di lembaga-lembaga pelatihan bahasa Korea.

Memperhatikan tiga masalah tersebut, Prodi Bahasa dan Kebudayaan Korea (selanjutnya disebut prodi) melakukan Pengabdian kepada Masyarakat (PkM) yang didesain untuk dilaksanakan secara berkelanjutan dalam menyikapi problema tersebut. Secara garis besar, $\mathrm{PkM}$ ini didesain untuk memberikan kontribusi secara langsung dalam 
menyelesaikan masalah tersebut dengan cara mengurai benang kusut yang menghambat maksimalnya tingkat kelulusan EPS-TOPIK di antara para peserta.

Selain itu, mengingat kerja sama Goverment to Government ( $\mathrm{G}$ to $\mathrm{G}$ ) antara Korea dan Indonesia dalam pengiriman PMI terus berjalan, maka kegiatan PkM ini didesain untuk memberikan sumbangsih nyata dalam mengatasi rendahnya penyerapan calon PMI ke Korea yang disebabkan oleh rendahnya kemampuan bahasa Korea mereka.

\section{Metode Pelaksanaan}

PkM yang berlangsung pada Jumat, 5 Oktober 2018 di ruang pertemuan kantor BP3TKI (Balai Pelayanan Penempatan dan Perlindungan Tenaga Kerja Indonesia) Yogyakarta ini adalah kegiatan perdana dari serangkaian $\mathrm{PkM}$ berkelanjutan yang terkait dengan penanganan permasalahan calon PMI yang dikirim ke Korea. Untuk itulah, PkM tertanggal 5 Oktober itu dapat disebut PkM tahap 1 yang bertujuan untuk memetakan kondisi kemampuan bahasa Korea calon PMI di daerah Yogyakarta. Dengan mengetahui kondisi kemampuan dan kelemahan dari para calon PMI, nantinya akan mempermudah prodi dalam merancang buku acuan pengajaran dan pembelajaran bahasa Korea berbasis pemecahan ujian EPS-TOPIK (Rencana PkM tahap 2). Selanjutnya, dengan berdasarkan buku tersebut, prodi berencana mengadakan pelatihan bahasa Korea berbasis EPS-TOPIK untuk seluruh pengajar calon PMI di Yogyakarta, bahkan seluruh Indonesia (Rencana PkM tahap 3).

Dalam kegiatan PkM tahap 1, Prodi sejak awal telah berencana untuk bekerja sama dengan BP3TKI Provinsi Daerah Istimewa Yogyakarta. Kemudian, kedua lembaga ini bersama-sama menentukan target kegiatan atau peserta, yang dalam hal ini adalah calon PMI yang sedang mengikuti kursus bahasa Korea di berbagai Lembaga Kursus \& Pelatihan (LKP) di provinsi DIY. Secara singkat, peserta yang mengikuti kegiatan ini berjumlah 48 orang dan berasal dari 5 LKP di DIY.

Acara berlangsung pada hari Jumat mulai pukul 08.30 hingga pukul 12.00 dengan lancar. Diawali dengan pembukaan dan acara seremonial yang tak memakan waktu lama, acara inti berupa try out test atau uji coba EPS-TOPIK pun dimulai. Semua soal EPS-TOPIK yang telah dipersiapkan dan digodok oleh Tim Prodi pun dibagikan kepada peserta mulai pukul 09.00. Dengan jumlah total 50 soal yang terdiri atas 25 soal Menyimak dan 25 soal Membaca, maka uji coba pun dilaksanakan. Mahasiswa prodi yang membantu $\mathrm{PkM}$ ini bertugas sebagai pengawas selama uji coba. Sementara itu, para dosen prodi bertugas sebagai pelaksana dan penanggung jawab selama uji coba ujian berlangsung, terutama untuk memastikan lancarnya ujian Menyimak. Hal itu untuk memastikan bahwa suara dan rekaman soal Menyimak dapat didengar dengan jelas oleh seluruh peserta ujian. Setelah itu, selama ujian Membaca, para dosen prodi juga terus memastikan agar para peserta dapat mengikuti uji coba dengan tenang dan baik. Pascauji-coba, para dosen memandu para peserta dalam memahami soal dan membahas kunci jawabannya.

Untuk itulah, setelah berakhir pada pukul 11.00, kegiatan uji coba dilanjutkan dengan sesi tanya jawab seputar EPS-TOPIK serta berbagai permasalahan terkait kesempatan bekerja di Korea. Walaupun waktu sangat terbatas, para peserta diberi kesempatan untuk bertanya secara bebas. Namun, yang paling penting adalah sesi 
pembahasan soal-soal ujian. Pada saat itulah para peserta dapat menanyakan beberapa hal terkait kesulitan dan hambatan dalam mengerjakan soal-soal EPS-TOPIK.

Pada saat yang sama, pada pukul 11.00 hingga 12.00, kaprodi dan sekretaris prodi mengadakan pertemuan terpisah dengan para pemilik dan penyelenggara LKP serta staf dari BP3TKI untuk membicarakan tindak lanjut terkait $\mathrm{PkM}$ ini. Dari beberapa hal yang dibicarakan, ada satu inti yang disepakati bersama, yaitu perlunya pelatihan bagi para pengajar bahasa Korea di LKP Bahasa Korea se-Indonesia. Hal ini mengingat bahwa rata-rata para pengajar di LKP adalah mantan pekerja migran Indonesia yang telah pulang ke Indonesia dan membuka lembaga-lembaga tersebut. Berdasarkan informasi-informasi yang diperoleh, terkuak keinginan besar mereka untuk meningkatkan kemampuan dalam bahasa Korea, mengingat tuntutan yang semakin tinggi dari para calon PMI untuk mendapatkan pengajaran yang maksimal. Untuk itulah, bak gayung bersambut, prodi, melalui kegiatan PkM ini, menyepakati untuk menjadikan hasil PkM ini sebagai batu pijakan awal untuk memulai kerja sama yang lebih luas dengan para LKP di bawah payung kerja sama dengan BP3TKI serta instansi terkait lain, seiring dengan perkembangan arah kerja sama tersebut.

Dari suasana dan keakraban yang terjalin selama kegiatan dapat disimpulkan bahwa berkat keterlibatan kuat dan efisien dari semua pihak, kegiatan uji coba pun berjalan sesuai rencana. Intinya, dengan bantuan dan kerja sama antara para staf prodi, mahasiswa prodi, para peserta, penyelenggara LKP, serta staf BP3TKI, maka dapat dikatakan bahwa kegiatan ini berlangsung sukses. Untuk memberikan apresiasi kepada para peserta, maka pada akhir acara diberikan secara gratis buku 99 Kiat Sukses Bekerja di Korea karya dosen prodi kepada seluruh peserta $\mathrm{PkM}$ ini.

\section{Keterlibatan Aktif “Masyarakat Sasaran” dalam PkM}

Dengan melibatkan para calon PMI beserta para pemilik LKP dari Provinsi DIY, prodi merangkul subjek penting dalam lingkaran pengiriman calon PMI ke Korea. Para calon PMI adalah anggota masyarakat yang ingin mengubah taraf kesejahteraan keluarganya, yang secara terbuka berniat untuk menjadi tenaga kerja migran di luar negeri. Dalam kegiatan ini, mereka menjadi inti kegiatan PkM karena

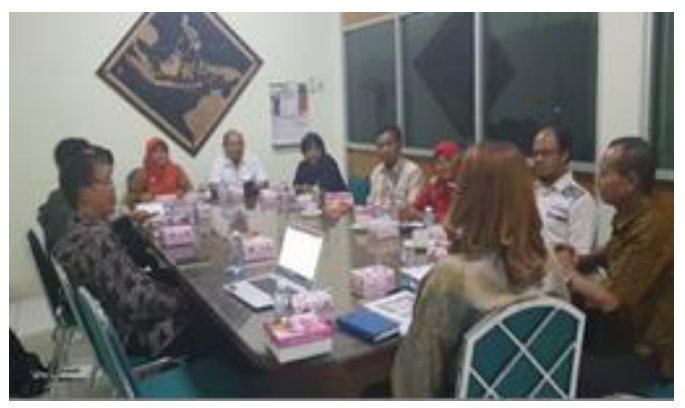

Ilustrasi 1. Pertemuan dengan Staf BNP2TKI, BP3TKI, Perwakilan LPK Yogyakarta merekalah yang datang ke tempat kegiatan untuk aktif mengikuti proses $\mathrm{PkM}$ ini.

Hal positif yang terlihat selama kegiatan adalah keaktifan dan keseriusan mereka dalam mengikuti try out tes EPS-TOPIK. Mereka pun mengetahui bahwa hasilnya akan digunakan sebagai dasar dan acuan utama untuk melihat kemampuan mereka. Lewat hasil itulah, prodi dapat memetakan kemampuan mereka sebagai dasar awal untuk rencana pembuatan buku "Bahasa Korea Berbasis Pemecahan Soal EPS-TOPIK"—yang dijadikan sebagai kegiatan PkM Tahap 2.

Sementara itu, selama kegiatan juga terlihat keaktifan para pemilik dan penyelenggara 
LKP yang secara langsung datang untuk mengantarkan para anak didiknya mengikuti PkM ini. Mereka pun dengan terbuka memberikan gambaran serta berbagi pengalaman dalam penyelenggaraan kursus bahasa Korea. Untuk itulah, prodi juga memproyeksikan bahwa mereka akan terus bekerja sama dengan tim prodi dalam penyusunan modul "Bahasa Korea Berbasis Pemecahan Soal EPS-TOPIK" bagi para pengajar. Hal ini sangat penting karena merekalah salah satu pihak yang akan menggunakan hasil dari proses $\mathrm{PkM}$ ini.

Bahkan, terkait dengan PkM Tahap 3 (pelatihan kepada para pengajar bahasa Korea di LKP-LKP), Prodi dapat memproyeksikan bahwa keterlibatan mereka sangatlah vital. Prodi berencana untuk mengundang para pengajar bahasa Korea di LKP untuk ikut dalam PkM selanjutnya, yaitu Training of Trainers atau pelatihan bagi para pengajar bahasa Korea untuk menyamakan visi atau bahkan metode dalam pengajaran bahasa Korea bagi para calon PMI.

Terakhir, walaupun bukan sebagai sasaran utama, terlibatnya BP3TKI Yogyakarta dalam PkM ini menunjukkan satu hal signifikan, yaitu peran aktif dari lapisan masyarakat lain, dalam hal ini adalah badan pemerintah.

\section{Gambaran Sekilas Kemampuan Para Calon PMI}

Seperti yang telah disebutkan di bagian awal tulisan ini, peserta uji coba EPS-TOPIK dalam kegiatan PkM ini berjumlah 48 orang yang berasal dari 5 buah LKP berbeda di Provinsi DIY, yaitu LKP Bina Insani (15 orang), LKP Wareng Eso (11 orang), LKP Rhona (10 orang), LKP Sejong (10 orang), dan LKP Nuha (2 orang). Dapat dikatakan bahwa mereka adalah wakil dari setiap LKP yang mengikuti kegiatan ini. Dari data BP3TKI Yogyakarta, tercatat ada 10 LKP di DIY yang menyelenggarakan pelatihan bahasa Korea bagi para calon PMI, maka keikutsertaan 5 LKP dalam kegiatan ini dapat dianggap sebagai representasi keadaan LKP di provinsi ini. Berikut ini adalah tiga hasil penting try out yang perlu dicermati.

Pertama, hasil uji coba menunjukkan bahwa 27 peserta (56\%) mendapatkan nilai Menyimak yang lebih rendah daripada nilai Membaca. Hal ini sesuai dengan prediksi awal bahwa 25 soal Menyimak EPS-TOPIK walaupun didesain dengan intonasi dan kecepatan yang perlahan tetaplah bagian ujian yang sulit bagi para pembelajar bahasa Korea yang belum terbiasa terpapar dengan berbagai bunyi, suara, intonasi, dan kecepatan dalam percakapan bahasa Korea. Soal ujian Menyimak didesain untuk diperdengarkan dua kali untuk setiap soal dengan derajat kesulitan yang semakin meningkat seiring bertambahnya nomor soal. Untuk itulah, nomor-nomor soal (18-25) adalah bagian yang sering dirasakan paling sulit buat para peserta ujian ini.

Banyaknya kesalahan yang terjadi di nomor-nomor tersebut menunjukkan bahwa para peserta atau calon PMI masih perlu memahami lebih lanjut percakapan panjang serta wacana-wacana dengan topik tertentu yang memerlukan konsentrasi lebih saat mengerjakan soal. Bila menilik lebih dalam lagi, hal ini mencerminkan dua hal, yaitu (a) pentingnya penambahan pengetahuan bagi para calon PMI mengenai berbagai situasi percakapan atau lebih tepatnya berbagai macam ungkapan dalam bahasa Korea yang perlu mereka ketahui dan kuasai untuk menghadapi soal Menyimak EPS-TOPIK serta (b) pentingnya latihan percakapan dalam kelas-kelas bahasa Korea di LKP. Selain untuk 
sekadar belajar soal EPS-TOPIK, percakapan ini diusahakan sebagai muatan penting yang dapat digunakan oleh para siswa kelak jika benar-benar tinggal dan bekerja di Korea.

Kedua, dari hasil ujian bagian Menyimak diketahui bahwa kemampuan para peserta masih lemah dalam memilah-milah antara informasi penting dan informasi tambahan. Selain tergantung dari daya konsentrasi setiap peserta, hal ini juga tergantung dari banyaknya kosakata yang harus mereka tangkap dan kuasai dalam mendengar dan menjawab soal. Salah satu contoh yang dapat diungkap di sini adalah dua soal terakhir dalam sesi Menyimak yang menguji kemampuan peserta untuk mengetahui detail percakapan dalam bahasa Korea. Tercatat ada 27 peserta (56\%) yang kesulitan menjawab soal-soal tersebut. Dua soal terakhir sesi Menyimak merupakan salah satu bagian ujian yang memerlukan pemahaman ekstra untuk dapat menjawabnya dengan tepat. Selain karena semakin panjangnya percakapan, kosakata yang digunakan pun semakin bervariasi dan derajat kesulitannya meningkat.

Berdasarkan hal tersebut, maka para peserta pelatihan bahasa Korea memerlukan penambahan jam-jam khusus pengayaan kosakata, terutama yang terkait dengan berbagai situasi nyata jika mereka benar-benar tinggal dan bekerja di Korea. Sebagai informasi, sesuai namanya, EPS-TOPIK adalah ujian bahasa Korea untuk para calon pekerja di perusahaan-perusahaan SME (Small Medium Enterprises), perusahaan, atau pabrikpabrik kecil menengah yang terkenal dengan sebutan "3D jobs" (dirty, dangerous, difficult jobs) atau pekerjaan yang kotor, berbahaya, dan sulit. Untuk itulah, penguasaan pekerja akan berbagai macam kosakata yang terkait dengan pekerjaan dan lingkungannya sangatlah penting. Hal itu dijamin dapat memberikan keamanan dan keselamatan selama bekerja di bawah kontrak 3 tahun 10 bulan.

Melihat hal tersebut, pelatihan khusus dan terus-menerus tetap diperlukan. Pelatihan yang tidak hanya menekankan penghafalan, namun juga pemahaman dan kemampuan menggunakannya dalam berbagai konteks kehidupan nyata di Korea, juga penting untuk para calon PMI tersebut. Oleh karena itu, selain tuntutan agar para calon PMI mampu menguasai hal tersebut, para pengajarnya pun dituntut untuk berusaha dan berbuat yang sama. Dalam hal ini berarti para pengajar di LKP juga perlu bekerja keras untuk menambah jam atau paling tidak memastikan bahwa muatan itu tersampaikan dan terserap oleh para calon PMI yang mereka ajar.

Ketiga, hasil sesi Membaca juga menunjukkan suatu hal yang menarik untuk diperhatikan. Terdapat 25 soal Membaca yang dirancang untuk mengukur kemampuan peserta dalam memahami teks bacaan, memahami kosakata, dan memahami kontekskonteks pemakaiannya. Dari jumlah itu, ada 5 soal terakhir yang berisi bacaan panjang yang menjadi bagian tersulit bagi 56\% atau 27 peserta ujian. Hasil ini sama dengan prediksi awal bahwa hanya mereka yang benar-benar terbiasa dengan bacaan panjang dan kosakata tingkat menengah saja yang akan dapat dengan mudah mengerjakannya. Hal itu dapat dilihat dalam contoh soal nomor 24-25 yang diberikan kepada para peserta (lihat halaman berikutnya).

Dalam soal bacaan yang tergolong panjang seperti di atas, banyak peserta terlihat kesulitan dalam menjawabnya. Pertama-tama, mereka harus mampu membaca bacaan tersebut dalam waktu yang singkat dan memahami isinya. Kemudian, mereka juga harus mampu menjawab dua pertanyaan terkait bacaan tersebut dalam waktu yang singkat pula. Dalam bacaan tersebut termuat beragam tata bahasa Korea serta kosakata 
[24-25] 다음 내용을 읽고 물음에 답하십시오.

저는 휴대폰 부품을 생산하는 공장에 다니고 있습니다. 1 일 3 교대로, 한 사람이 하 루에 8 시간씩 일을 합니다. 그렇지만 저는 하루에 10 시간씩 일을 하고 있습니다. 일 을 더 많이 하면 초과 수당을 받을 수 있기 때문입니다. 돈을 많이 벌어서 고향에 돌아가 집을 사고 싶습니다. 몸이 아프면 일을 할 수 없기 때문에 건강에 조심하고 있습니다. 건강을 위해서 일요일에는 일을 하지 않고 집 근처 산에 가서 맑은 공기 도 마시고 운동도 합니다.

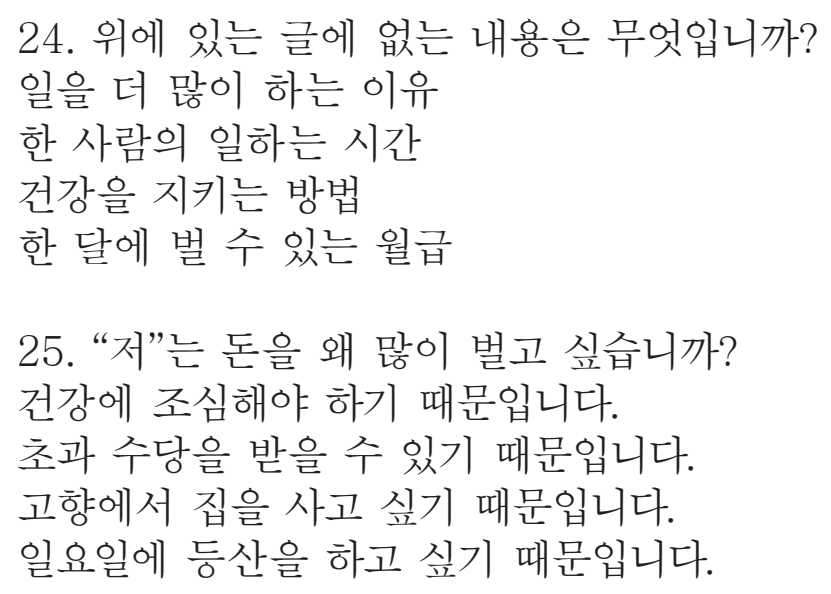

yang tidak sederhana. Namun, kemampuan membaca cepat dan memahami isi saja tak cukup karena mereka juga harus lebih berhati-hati supaya tidak terjebak dalam menjawab pertanyaan. Seperti halnya pertanyaan nomor 24, peserta diminta untuk menjawab yang tidak tercantum (글에 없는 내용) dalam bacaan di atas. Pada pertanyaan yang terlihat sederhana tersebut, banyak peserta yang melakukan kesalahan dalam menjawabnya. Selain disebabkan oleh kurangnya ketelitian, mereka yang dapat memahami pertanyaan pun harus berpikir lebih keras untuk memilih opsi jawaban yang ada. Sama halnya dengan nomor 25 yang memaksa peserta ujian untuk menyimpulkan teks bacaan agar dapat menjawab pertanyaan nomor tersebut.

Intinya, soal-soal sesi Membaca di bagian akhir memang didesain sedemikian rupa untuk mengukur logika peserta dalam memahami teks dalam bahasa Korea. Menariknya, untuk soal-soal Membaca yang berisi gambar, para peserta tidak mendapati kesulitan yang berarti seperti pada contoh soal berikut ini.

1-4다음 그림을 보고 맞는 답을 고르십시오 (Lihatlah gambar dan pilihlah jawaban yang tepat)

1.

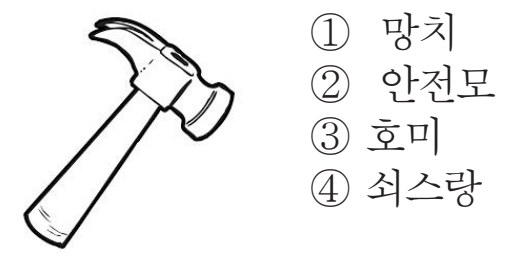


3.

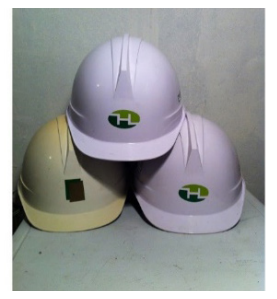

(1) 안전벨트가 네개 있습니다.

(2) 안전벨트가 세개 있습니다.

(3) 안전모가 세개 있습니다.

(4) 안전모가 네개 있습니다

Soal Membaca seperti contoh di atas tidak menjadi masalah besar karena hal itu sudah menjadi kisi-kisi kemampuan dasar para calon PMI ke Korea. Dengan kata lain, halhal itu sudah menjadi salah satu topik yang wajib mereka kuasai dan ketahui jika ingin bekerja di Korea. Dilihat dari segi tipe soalnya, maka soal seperti itu dapat dengan mudah dipahami dan dipelajari. Sebagai tambahan, EPS-TOPIK didesain untuk melihat kemampuan para calon PMI dalam beradaptasi dengan lingkungan kerja mereka.

Namun, soal-soal bacaan seperti nomor 24 dan 25 atau bagian-bagian akhir, walaupun terkait dengan topik pekerjaan mereka, tipe soal yang berupa teks panjang, memang memerlukan daya konsentrasi ekstra dan menuntut adanya pengetahuan yang lebih luas dari para peserta ujian EPS-TOPIK.

Itulah tiga gambaran singkat terkait hasil Try Out ujian EPS-TOPIK yang dilakukan terhadap 48 peserta kursus bahasa Korea di 5 LKP di Yogyakarta. Sekali lagi, ini adalah hasil awal yang akan dijadikan sebagai dasar bagi prodi dalam menyusun buku ajar serta panduan untuk memulai kerja sama yang lebih besar dan bermanfaat dengan LKP dan BP3TKI serta pihak-pihak yang terkait dengan pengiriman PMI ke Korea.

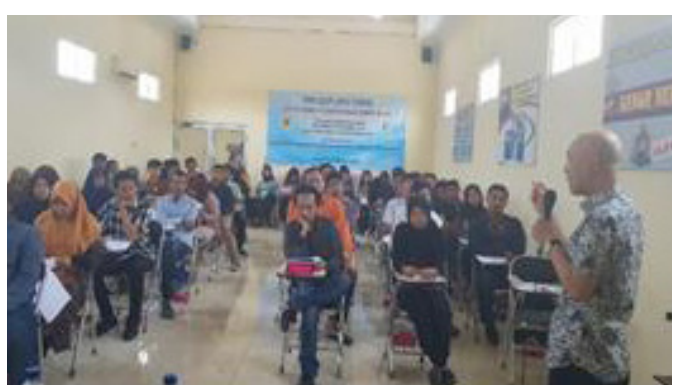

Ilustrasi 2. Suasana Tanya Jawab seputar EPS TOPIK \& Bekerja di Korea

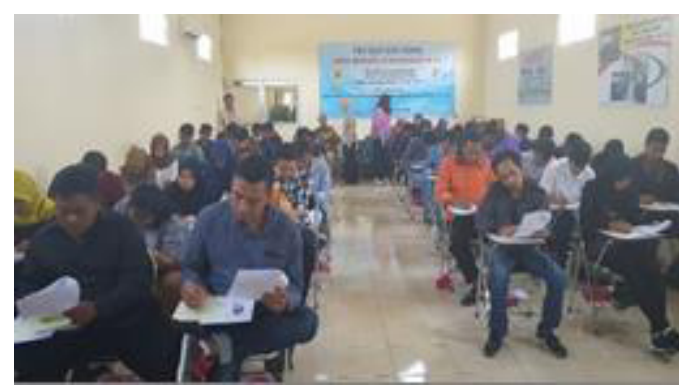

Ilustrasi 3. Suasana Pelaksanaan Uji Coba EPS TOPIK

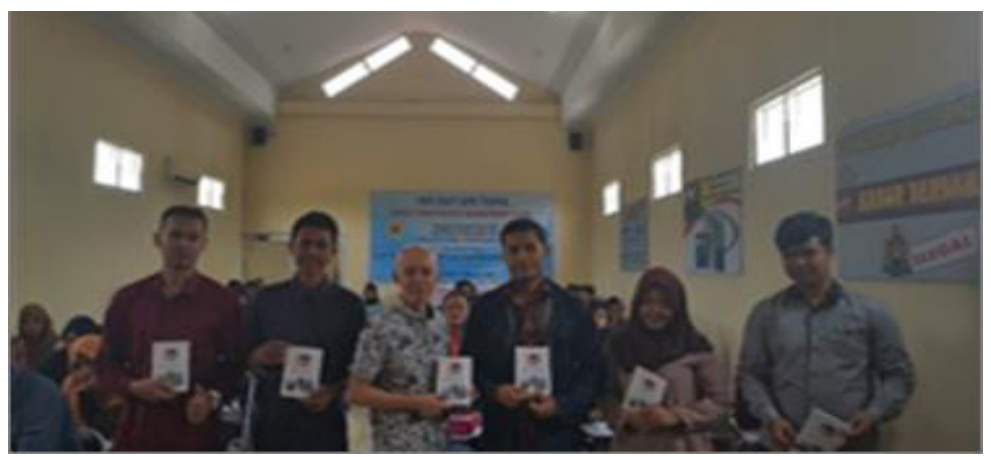

Ilustrasi 4. Pemberian Buku 99 Kiat Sukses di Korea bagi semua peserta PkM 


\section{Penutup}

Itulah gambaran dan hasil yang dapat diteropong melalui Pengabdian kepada Masyarakat yang dilakukan oleh Prodi Bahasa dan Kebudayaan Korea. Prodi telah merancang kegiatan lanjutan terkait $\mathrm{PkM}$ ini dan telah mengajak lembaga lain untuk mendukung dan saling bekerja sama demi terlaksananya program-program selanjutnya. Yang pasti, hal ini bertujuan untuk menghindari hasil PkM yang hanya ada di atas kertas. Untuk itulah, prodi bekerja sama dengan BP3TKI Yogyakarta mengundang Direktur Pelayanan Penempatan Pemerintah BNP2TKI (Badan Nasional Penempatan dan Perlindungan Tenaga Kerja Indonesia); Badan Standardisasi Kompetensi dan Pelatihan Kerja Ditjen Binalattas Kemnaker; Dinas Pendidikan, Pemuda dan Olahraga DIY; Disnakertrans Kabupaten Bantul, Gunungkidul, Kulon Progo, dan Sleman untuk diberitahu mengenai hasil PkM dan membicarakan berbagai kemungkinan dilanjutkannya PkM ini dalam bentuk-bentuk kerja sama yang lain. 